\title{
The atlanto-occipital joint: a concise review of its anatomy and injury
}

\author{
Gergely Bodon $^{1-3}$, Paul J. Choi ${ }^{4}$, Joe Iwanaga ${ }^{4}$, R. Shane Tubbs ${ }^{4,5}$ \\ ${ }^{1}$ Department of Orthopaedic Surgery, Klinikum Esslingen, Esslingen, Germany \\ ${ }^{2}$ Laboratory for Applied and Clinical Anatomy, Department of Anatomy, Histology and Embriology, Semmelweis University Budapest, Budapest, Hungary \\ ${ }^{3}$ Clinical Anatomy Tïbingen, University of Tübingen, Tïbingen, Germany \\ ${ }^{4}$ Seattle Science Foundation, Seattle, WA, USA \\ ${ }^{5}$ Department of Anatomical Sciences, St. George's University, Grenada, West Indies
}

\begin{abstract}
The atlanto-occipital joint (AOJ) is an important transitional region, which supports and stabilizes the cranium to the spine with its surrounding ligamentous structures. An injury to this joint is often accompanied by brain injury and may be fatal. A good understanding of the anatomy of this joint is required to timely diagnose an AOJ instability and intervene via the means of an immediate fixation. We discuss the normal anatomy of and anatomical variations within the occipito-atlantoaxial complex, the classification systems to describe its disruption, and its clinical significance.
\end{abstract}

Keywords: anatomy; craniocervical junction; injury; ligaments; trauma

Anatomy 2017;11(3):141-145 (2017 Turkish Society of Anatomy and Clinical Anatomy (TSACA)

\section{Introduction}

Injuries to the atlanto-occipital joint (AOJ) (Figure 1) make up $15-30 \%$ of all cervical spine injuries and $19 \%$ of such injuries are fatal. ${ }^{[1]}$ These injuries are more common in children due to the laxity of surrounding ligaments around the AOJ. ${ }^{[1]}$ The AOJ connects the occipital condyles (OC) (Figure 2) and the superior articular surfaces (SAS) (Figure 3) of the lateral mass of the atlas. ${ }^{[2]}$ The mean length, width, and height of the OC are 23.6 $\mathrm{mm}$ (a range of 16.7-30.6 mm), $10.5 \mathrm{~mm}$ (a range of $6.5-15.8 \mathrm{~mm}$ ), and $9.2 \mathrm{~mm}$ (a range of $5.8-18.2 \mathrm{~mm}$ ), respectively. ${ }^{[3]}$ The long condylar axes converge medially, forming the sagittal intercondylar angle, which ranges from 22 to $103^{\circ}$ (mean of 59.3 ${ }^{\circ} .^{[2]}$ The mean distance between the resultant anterior ends of the OCs, which is closer to the midline, is $23.6 \mathrm{~mm}$ (a range of $16-30 \mathrm{~mm}$ ) and that of the posterior ends (Figure 4), which are located just anterior to the equator of the foramen magnum, is $42.1 \mathrm{~mm}$ (a range of 37-50 mm). ${ }^{[3]}$ The OCs can be categorized according to their various shapes such as oval in $50 \%$ of all cases, S-shaped in $23.2 \%$, and triangular in $9 \%{ }^{[3]}$ Another classification is possible with the lengths of the OC, which is $26 \mathrm{~mm}$ in $77.2 \%$ of the cases: short OCs (less than $20 \mathrm{~mm}$ ) in $8.6 \%$ and long OCs (greater than 26 $\mathrm{mm}$ ) in $14.1 \%{ }^{\left[{ }^{[3}\right.}$ The alar ligament attaches to the medial surface of the OC..$^{[3]}$

The atlas is made up of two lateral masses, which are connected together by an anterior arch and a posterior arch. $^{[2]}$ The lateral masses bear the weight of the cranium. ${ }^{[4]}$ The SAS of the atlas is concave (Figure 5), forming a framework for the convex OCs, and is on the superior aspect of the lateral mass, which is trapezoid in shape and higher laterally ( $22 \mathrm{~mm}$; a range of $17.5-28.5 \mathrm{~mm}$ ) than it is medially $(11 \mathrm{~mm}$; a range of $8.2-14.6 \mathrm{~mm}){ }^{[4]}$ The SAS slopes medially with a mean angle of $22.4^{\circ}$ (a range of $16.5-29.2^{\circ}$ ) and converges medially with a mean horizontal angle of $18.6 \mathrm{~mm}$ (a range of $15.5-21.8 \mathrm{~mm}$ ). ${ }^{[4]}$ The surface of the AOJ has a $\mathrm{C}$-shape and is concave medially. The AOJ is reinforced by a joint capsule. ${ }^{[2]}$

\section{Atlanto-Occipital Ligaments}

The ligamentum nuchae ( $\mathrm{LN})$ is a continuation of the supraspinous ligament, which spans from the occipital protuberance to the vertebra prominens $(\mathrm{C} 7){ }^{[5]}$ The $\mathrm{LN}$ 
limits excessive neck flexion. ${ }^{[5]}$ The alar ligament (AL) (Figure 6) limits axial rotation and lateral flexion, stabilizing the AOJ. The AL is the primary ligament for the stabilization of the joint when the transverse ligament is damaged. ${ }^{[5]}$ The AL also anchors the dens to the OCs and is very tough ${ }^{[6]}$ The anterior and posterior atlanto-occipital membranes attach to their respective surfaces on the atlas and the foramen magnum. ${ }^{[5]}$ The apical ligament (Figure 6) joins the tip of the odontoid process to the basion (the most anterior point of the foramen magnum in the median sagittal plane) and has no mechanical role and is absent in $20 \%$ of the bodies studied by Tubbs et al. ${ }^{[5]}$ The AOJ allows $11-13^{\circ}$ of freedom, allowing for $25^{\circ}$ of flexion and extension, $5^{\circ}$ of axial rotation, and combined motions. ${ }^{[7]}$ Flexion is limited by the contact between the foramen magnum and the dens. ${ }^{[7]}$

According to Tubbs et al., the tectorial membrane (TM) (Figure 6), a mean thickness of $1 \mathrm{~mm}$, firmly attaches cranial base and body of the axis. ${ }^{[8]}$ The TM stabilizes the head in flexion and extension of the neck. ${ }^{[8]}$ It also carries a function of limiting the posterior movement of the odontoid process and prevents the process from intruding into the cervical canal and compress the spinal cord. $^{[8]}$

The lateral atlanto-occipital ligament (LAO) is situated right against the rectus capitis lateralis bilaterally and is

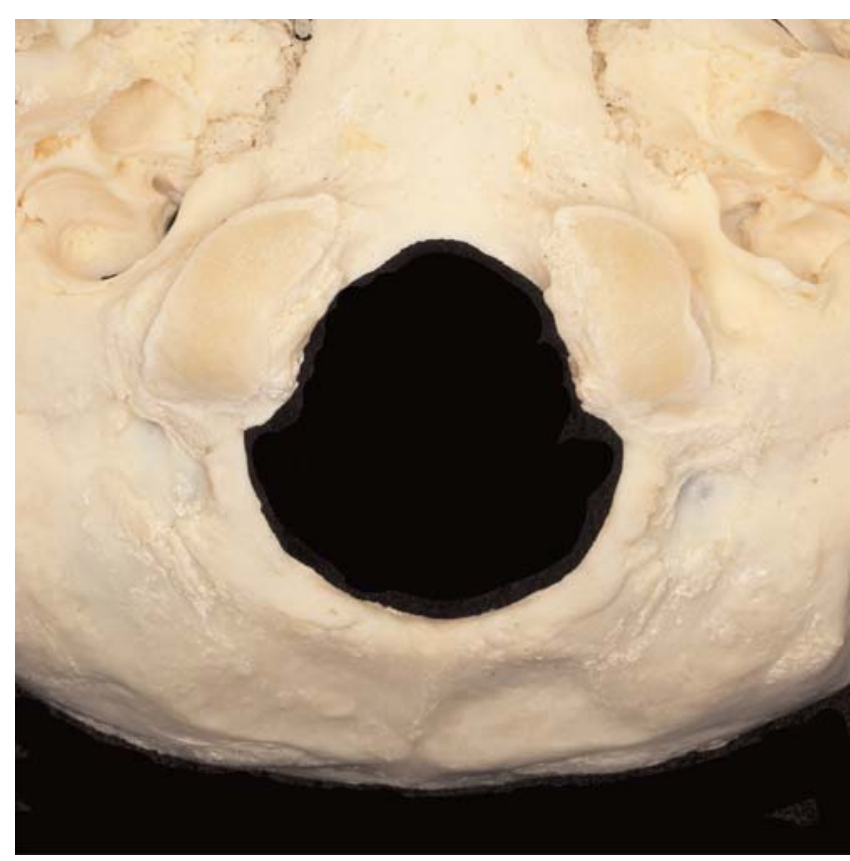

Figure 2. Inferior view of the skull base noting the occipital condyles along the anterior border of the foramen magnum. [Color figure can be viewed in the online issue, which is available at www.anatomy.org.tr]

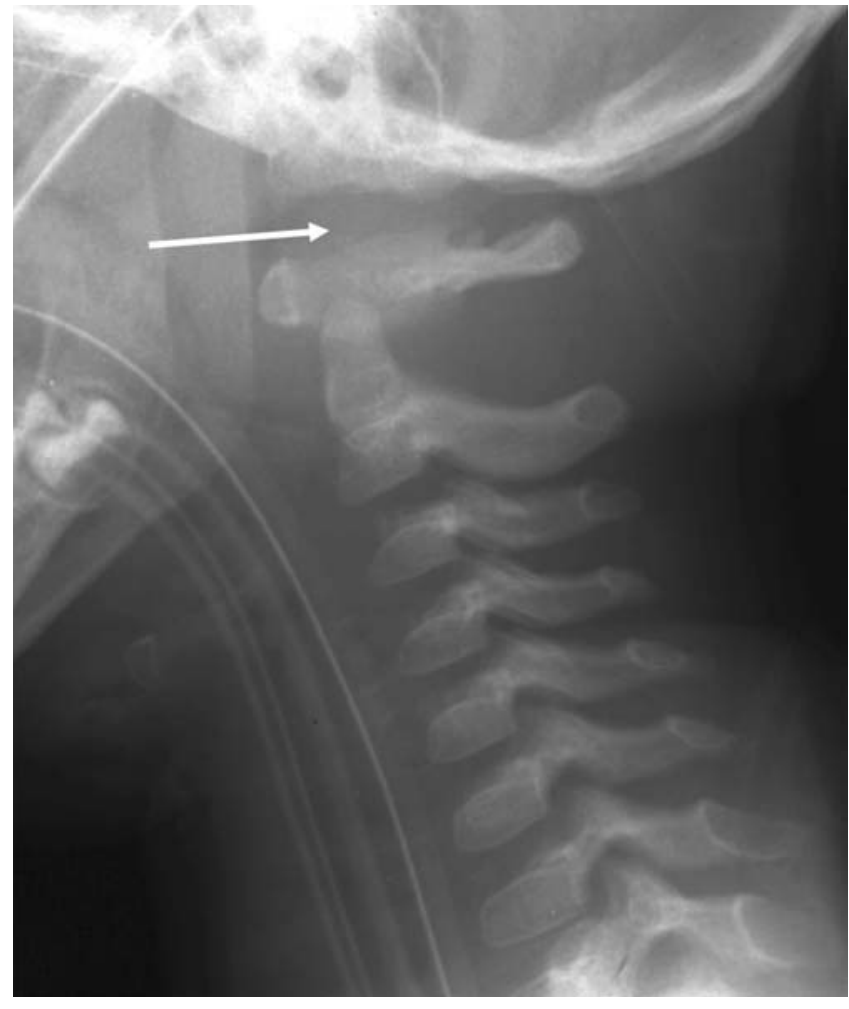

Figure 1. Lateral radiograph of the head and cervical spine noting separation injury of the craniocervical junction following an automobile accident. Note the increased space (arrow) between the occipital bone and first cervical vertebra.

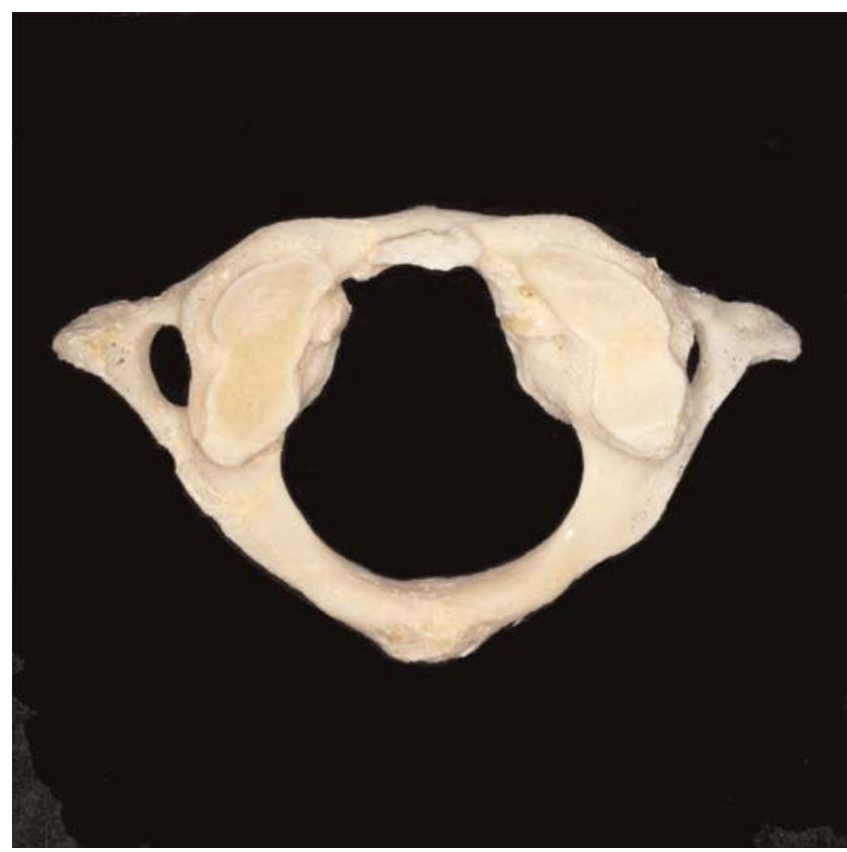

Figure 3. Superior view of the superior articular processes of $C 1$. [Color figure can be viewed in the online issue, which is available at www.anatomy.org.tr] 


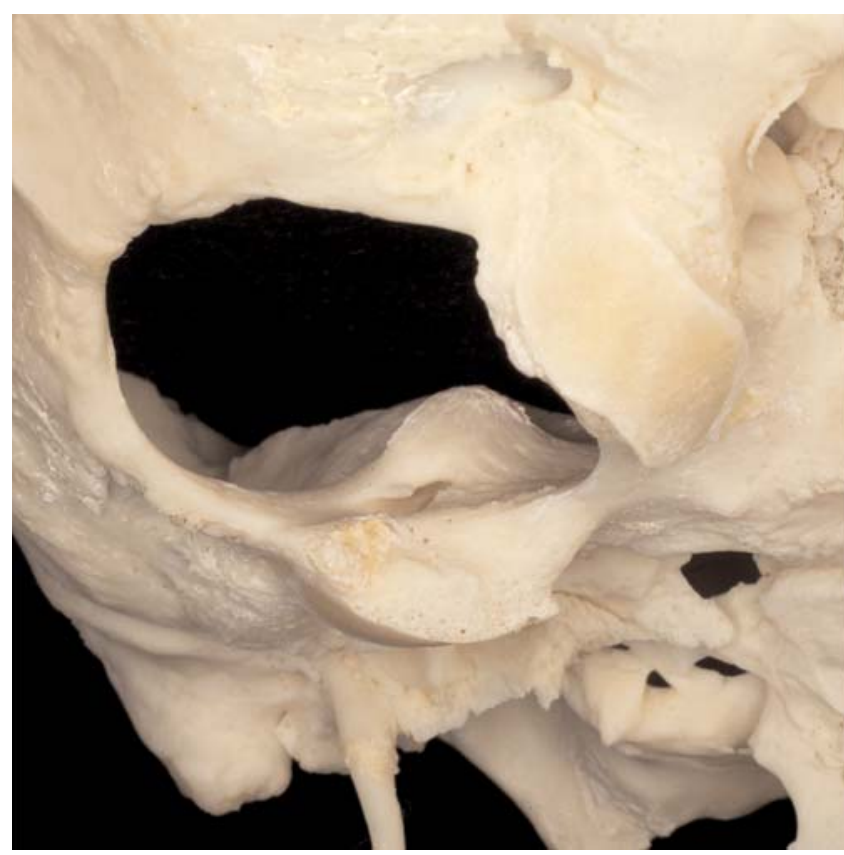

Figure 4. Inferolateral view of the occipital condyles of the occipital bone. [Color figure can be viewed in the online issue, which is available at www.anatomy.org.tr]

in a close contact with the jugular foramen anteriorly and the vertebral artery posteriorly. ${ }^{[9]}$ The ligament originates from the anterolateral aspect of the transverse process of the atlas and inserts onto the jugular process of the occiput. ${ }^{[9]}$ LAO has a mean angle of $26^{\circ}$ from the midline and a mean length and width of 2.2 and $0.5 \mathrm{~cm}$, respectively. ${ }^{[9]}$ This ligament limits lateral flexion of the neck and partially limits neck rotations bilaterally at the AOJ. ${ }^{[9]}$

The alar ligaments (AL) (Figure 6) are dense structures that connect the odontoid process to the medial aspect of the OCs. ${ }^{[10]}$ The ALs join the superior half of the lateral aspect of the dens and the medial surface of the OC, at which the distal insertions of the ligaments are limited. ${ }^{[10]}$ They limit the axial rotation, lateral flexion, and sagittal flexion at the AOJ. The alar ligaments are some of the most important structures around the AOJ, which not only protects but also allows mobility of the neurovascular bundles which run within the cervico-cranial junction. ${ }^{[10]}$

\section{Injuries to the AOJ}

In a traumatic injury involving the AOJ, its supporting ligaments may be torn and dislocate the atlas from the occiput. ${ }^{[1]}$ Such an injury is classically associated with a high-energy impact trauma in a road traffic accident or a fall from a height. ${ }^{[1]}$ According to Horn et al., the presence of an atlanto-occipital dislocation must be assessed in all

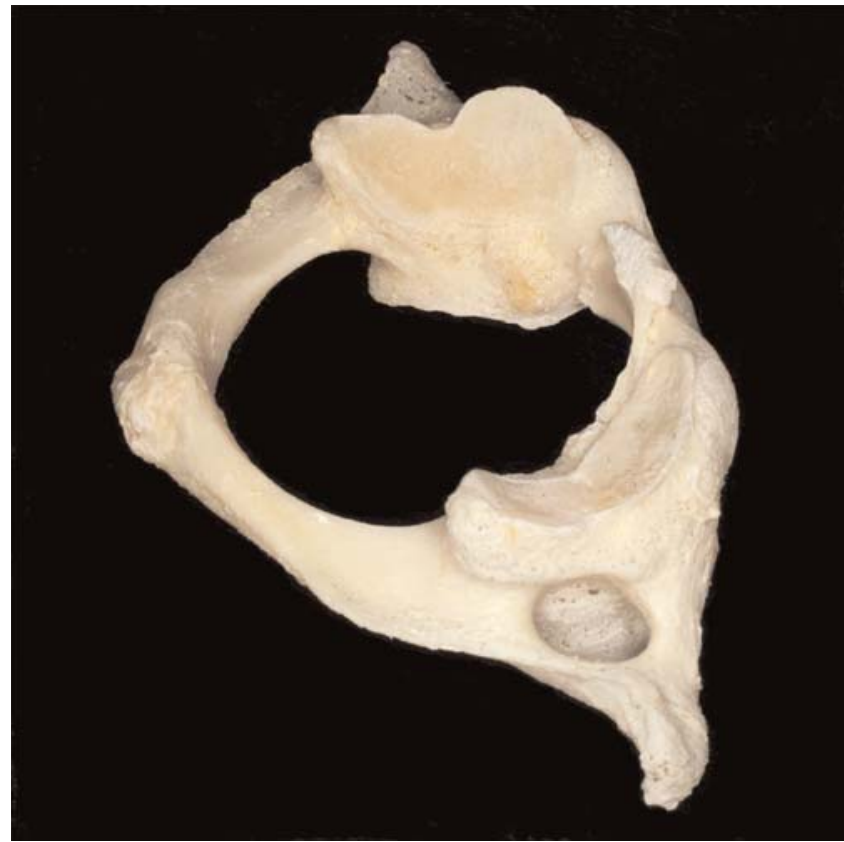

Figure 5. Lateral view of the superior articular processes of C1. [Color figure can be viewed in the online issue, which is available at www. anatomy.org.tr]

traumatic brain injuries. ${ }^{[12]}$ Most cases of dislocation require immediate stabilization. ${ }^{[12]}$

There are two types of atlanto-occipital injuries: atlanto-occipital dislocation (Figure 1) and OC fractures. A damage to the ligaments in this region may cause vary-

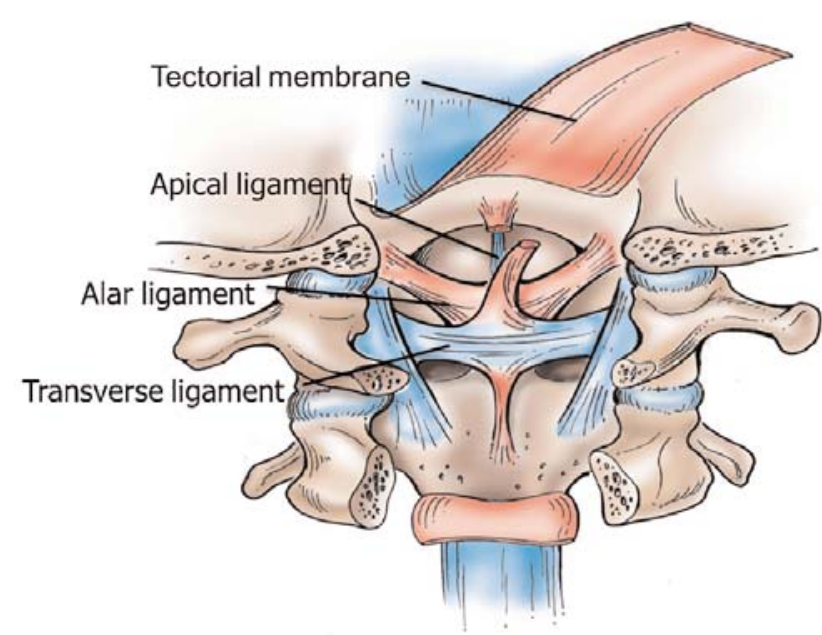

Figure 6. Posterior view of the ligaments of the craniocervical junction. Note that the tectorial membrane has been cut and reflected superiorly and inferiorly. [Color figure can be viewed in the online issue, which is available at www.anatomy.org.tr] 
ing degrees of atlanto-occipital instability and subluxation or luxation of the joint between the atlas and the axis. ${ }^{[13]}$ Traynelis et al. classified atlanto-occipital injuries according to the direction of the dislocation: type 1 - anterior dislocation, type 2 - vertical displacement, and type 3 - posterior dislocation. ${ }^{[13]}$

The radiologic diagnosis of atlanto-occipital injuries is challenging. The basion to dens interval (BDI), the distance between the basion and the tip of the dens, and the basion to axial interval (BAI), the distance between the basion and a line drawn at the posterior border of the body of the C2 and dens extended cranially, should be less than $12 \mathrm{~mm}$ in a lateral cervical radiograph to rule out an atlanto-occipital dissociation. ${ }^{[14]}$

The intraarticular fluid sign is shown by the magnetic resonance imaging $(\mathrm{MRI})$ and indicates a disrupted AOJ capsule and an injury to the surrounding ligaments. ${ }^{[15]}$ The revised $\mathrm{OC}$ to $\mathrm{C} 1$ interval (CCI) shown by the computed tomography (CT) is highly sensitive and specific for an atlanto-occipital injury and is measured from the bottom of the $\mathrm{OC}$ to the deepest point in the valley of the SAS of $\mathrm{C} 1$ in the parasagittal plane. ${ }^{[15]} \mathrm{A}$ CCI of greater than $2.5 \mathrm{~mm}$ is considered diagnostic of unilateral or bilateral AOJ dislocation. ${ }^{[15]}$

A fracture of the OC is relatively rare and two classification systems are utilized. Anderson and Montesano developed three categories of OC fractures: type I impaction fracture of the $\mathrm{OC}$, which is considered stable, type II - fracture of the skull base in which the fracture line crosses the OC, type III - avulsion fracture of the OC resulting in ligamentous instability. ${ }^{[16]}$ Types I and II fractures are stable while type III fracture is unstable. ${ }^{[16]}$ Tuli et al. ${ }^{[17]}$ reported a classification system in regards to the presence of dislocation, which is defined by more than $2 \mathrm{~mm}$ of separation, or occipito-atlantoaxial instability: type 1 OC fracture without dislocation and type 2 - dislocated OC fracture. Type 2 is further subdivided into $2 \mathrm{a}$, which is a case of a stable occipito-atlantoaxial complex, and $2 \mathrm{~b}$, which is a case with any signs of occipito-atlantoaxial instability. A surgery is required only in cases of presence of an instability or a compression of the neural structures, both of which are rare. ${ }^{[17]}$

\section{Conclusion}

The AOJ (Figures 7 and 8 ) is the articulation point of the $\mathrm{OC}$ and the SAS of the atlas. The structure of this joint is maintained and reinforced by multiple surrounding ligaments, which allow the spinal cord to pass through the foramen magnum without any bony interference. Contact sports and high-impact collisions are the common mechanisms of injury to the AOJ and may be fatal. A timely

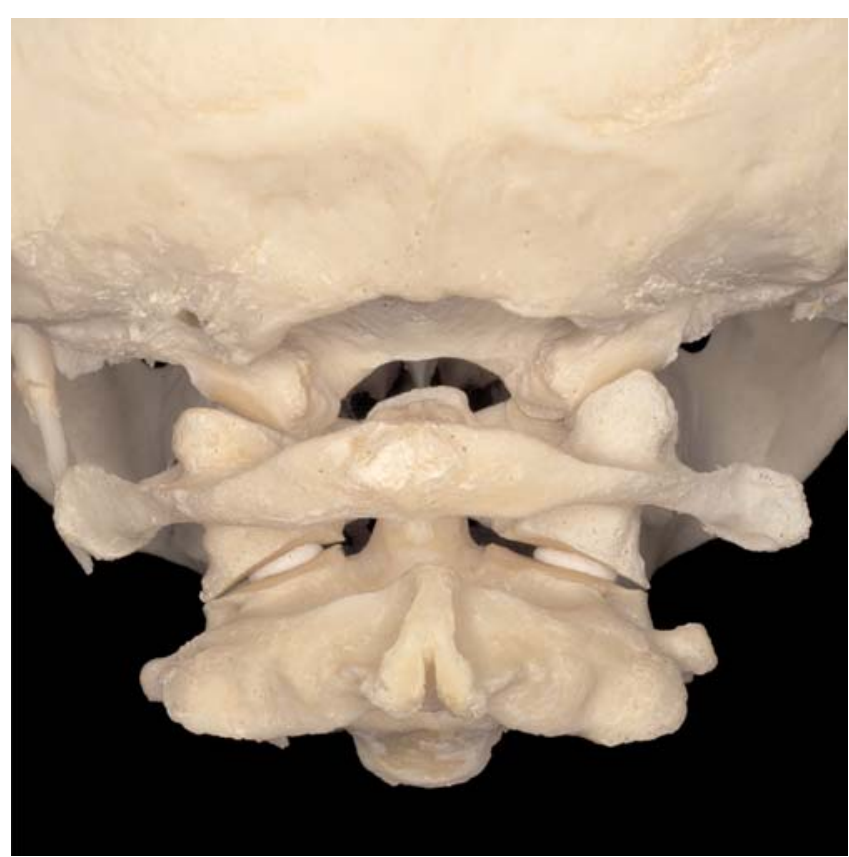

Figure 7. Posterior view of the craniocervical junction noting the articulation between the occipital condyles and superior articular facets of C1. [Color figure can be viewed in the online issue, which is available at www. anatomy.org.tr]

diagnosis of AOJ injuries increases the likelihood of survival. ${ }^{[1]}$ In addition, subluxations can also be caused by ligament laxity and muscular atrophy in osteoarthritis. ${ }^{[5]}$

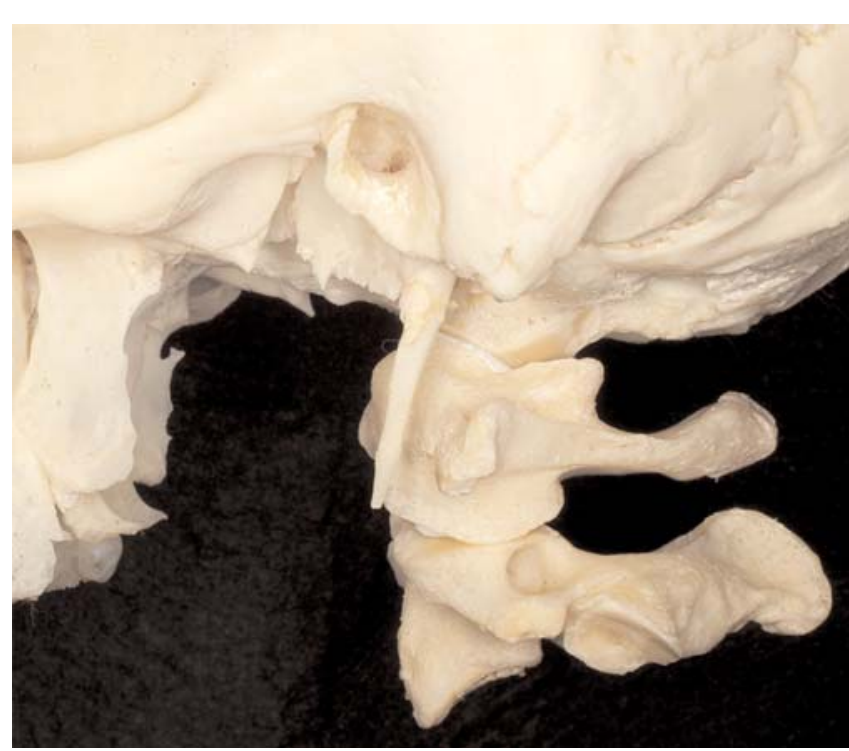

Figure 8. Lateral view of the craniocervical junction noting the articulation between the occipital condyles and superior articular facets of C1. [Color figure can be viewed in the online issue, which is available at www. anatomy.org.tr] 


\section{References}

1. Bucholz RW, Burkhead WZ, Graham W, Petty C. Occult cervical spine injuries in fatal traffic accidents. J Trauma 1979;19:768-71.

2. Netter F. Atlas of human anatomy. 6th ed. Philadelphia (PA), USA: Saunders; 2014.

3. Naderi S, Korman E, Citak G, Güvençer M, Arman C, Senoğlu M, Tetik S, Arda MN. Morphometric analysis of human occipital condyle. Clin Neurol Neurosurg 2005;107:191-9.

4. Kandziora F, Schulze-Stahl N, Khodadadyan-Klostermann C, Schröder R, Mittlmeier T. Screw placement in transoral atlantoaxial plate systems: an anatomical study. J Neurosurg 2001;95(1 Suppl):80-7.

5. Tubbs RS, Hallock JD, Radcliff V, Naftel RP, Mortazavi M, Shoja MM, Salter EG, Acakpo-Satchivi L, Wellons JC 3rd, Blount JP, Oakes WJ. Ligaments of the craniocervical junction. J Neurosurg Spine 2011;14:697-709.

6. O'Rahilly R, Meyer DB. The timing and sequence of events in the development of the human vertebral column during the embryonic period proper. Anat Embryol (Berl) 1979;157:167-76.

7. Hall GC, Kinsman MJ, Nazar RG, Hruska RT, Mansfield KJ, Boakye M, Rahme R. Atlanto-occipital dislocation. World J Orthop 2015;6:236-43.

8. Tubbs RS, Kelly DR, Humphrey ER, Chua GD, Shoja MM, Salter EG, Acakpo-Satchivi L, Wellons JC 3rd, Blount JP, Oakes WJ. The tectorial membrane: anatomical, biomechanical, and histological analysis. Clin Anat 2007;20:382-6.
9. Tubbs RS, Stetler W, Shoja MM, Loukas M, Hansasuta A, Liechty P, Acakpo-Satchivi L, Wellons JC, Blount JP, Salter EG, Oakes WJ. The lateral atlantooccipital ligament. Surg Radiol Anat 2007;29:21923.

10. Iwanaga J, Sardi J, Voin V, Chapman JR, Oskouian RJ, Tubbs RS. Anatomy of alar ligament part I: morphometrics and variants. World Neurosurg 2017;107:1001-6.

11. Labler L, Eid K, Platz A, Trentz O, Kossmann T. Atlanto-occipital dislocation: four case reports of survival in adults and review of the literature. Eur Spine J 2004;13:172-80.

12. Horn EM, Feiz-Erfan I, Lekovic GP, Dickman CA, Sonntag VK, Theodore N. Survivors of occipitoatlantal dislocation injuries: imaging and clinical correlates. J Neurosurg Spine 2007;6:113-20.

13. Traynelis VC, Marano GD, Dunker RO, Kaufman HH. Traumatic atlanto-occipital dislocation. Case report. J Neurosurg 1986;65:86370 .

14. Harris JH, Carson GC, Wagner LK, Kerr N. Radiologic diagnosis of traumatic occipitovertebral dissociation: 2. Comparison of three methods of detecting occipitovertebral relationships on lateral radiographs of supine subjects. AJR Am J Roentgenol 1994;162:887-92.

15. Dahdaleh NS, Khanna R, Menezes AH, Smith ZA, Viljoen SV, Koski TR, Hitchon PW, Dlouhy BJ. The application of the revised condyle-C1 interval method to diagnose traumatic atlanto-occipital dissociation in adults. Global Spine J 2016;6:529-34.

16. Anderson PA, Montesano PX. Morphology and treatment of occipital condyle fractures. Spine (Phila Pa 1976) 1988;13:731-6.

17. Tuli S, Tator CH, Fehlings MG, Mackay M. Occipital condyle fractures. Neurosurgery 1997;41:368-76.

Correspondence to: Paul J. Choi, MD

Seattle Science Foundation, 550 17th Ave, James Tower,

Suite 600, Seattle, WA 98122, USA

Phone: +1 2067326500

e-mail: paulchoi92@gmail.com

Conflict of interest statement: No conflicts declared.

This is an open access article distributed under the terms of the Creative Commons Attribution-NonCommercial-NoDerivs 3.0 Unported (CC BY-NCND3.0) Licence (http://creativecommons.org/licenses/by-nc-nd/3.0/) which permits unrestricted noncommercial use, distribution, and reproduction in any medium, provided the original work is properly cited. Please cite this article as: Bodon G, Choi PJ, Iwanaga J, Tubbs RS. The atlanto-occipital joint: a concise review of its anatomy and injury. Anatomy 2017;11(3):141-145. 